\title{
The Logic of THE Collection
}

\section{Boris Groys}

In our culture 'serious', 'autonomous', art is produced primarily to be collected. Unlike in the past, it is no longer conceived as an element of a temple, a church, a palace or a functional, public space. It is even possible to argue that the modern notion of 'art' is a result of the emerging of the modern museum in the 18 th century. The historical museum didn't collect art but rather produced it through displaying the very heterogeneous objects which were used in many different-sacred, political, ritual, decorative etc - ways in their original cultural contexts inside the unified and secularized space of the aesthetic presentation in the museum.

The conscious production of art as art in the modern sense of this word began to be possible only after the creation of the museum's neutral, purely aesthetic space of display. This modern art production can be understood as an expansion of the collecting strategies in the realm of the profane and unspectacular. The historical museum collected the already established cultural values and at the same time 'devaluated' them from the highest religious or 'life' values into art. The 'Museum of Contemporary Art', or 'The Museum of Modern Art', or 'The Museum of 20th Century Art' etc. is collecting the profane objects of the everyday life or of the socially deviant, but as not valuable regarded practices, and 'revaluates' them into art. In this way the modern museum creates a universal space of historical comparison which allows us to put in this comparison our own present and possible future. The modern art production can be seen as such a self contextualization of our own modernity inside the museum space of universal historical comparison.

\section{I}

The modern art is in fact destined from the start for the isolated, 'autonomous' space of public or private collections. In this way, art output today differs considerably from all other modern forms of production. All our other products are targeted to be consumed within the frame of our economy. But to consume means at the same time to destroy. A piece of bread is eaten and afterwards it does not exist any more. A car is driven for a while and then it is considered to be physically or morally outdated and is scraped. Maga- 
74 zine articles or scientific treatises are read, digested and then forgotten in their original form. If you want to give an account of the respective information, you do so in your own words. The text as an object is also consumed, annulled and destroyed at the moment that it is digested.

By contrast, a work of art is not consumed as an object, but rather preserved: It may not be eaten, used or completely understood. Firmly established convention protects the work of art from material disappearance, from the exhaustion in the process of using it as information, or from definitive dissolution in the variety of interpretations. Of course, works of art are not only worth something in ideal terms; they are also worth something in terms of money. Therefore, all works of art are goods as well, but they are not consumer goods. They are rather collectors' goods, and for that reason they are subject to another kind of economics than the economics of consumer markets. What right does a particular work of art have to be collected and preserved if this right does not spring from its actual market value? What other ideal criteria, if you will, does the work of art have to meet in order to make it worth collecting?

There are as many answers to these questions as there are theories of art. But all the answers that I am familiar with have something in common: they look for the criteria of the collection value beyond the collection itself, that is to say in another outer reality, however that is to be understood. It can be claimed, for example, that a work of art should be valid for eternity to merit permanent preservation in a collection, in which case it should embody everlasting beauty, superior quali- ty, the divine, the human, the formally and qualitatively perfect, the sensible, the geometrical, the passionate, the natural, the unconscious, the erotic, the linguistic, the socially critical, the democratic, and, as far as I am concerned, the everlasting deconstructivistic as well. But all these answers are very problematic because if a work of art embodies in itself something everlasting it would be superfluous to preserve it additionally. It would rather make more sense to care for something that is fragile and mortal. For that matter, a piece of bread, an old car, or an outdated piece of news could also be collected and preserved as works of art so that, as a consequence, they are transferred to another kind of economics. The question about the reason for preservation is actually only avoided when it is answered with the remark that the respective work of art is in itself already significant and worth preserving.

It has further been claimed that particularly in modern art the decision about what a work of art is worth has become unrestrained, arbitrary and subjective. What is collected is that which pleases the individual who has emancipated himself from all preconceived criteria of worth. In practice, however, the collection is not based on personal or even social taste. We collect and consider works of art as valuable which seem to be important, relevant and significant to us - and not necessarily those that we like. The art of the avantgarde in particular has theoretically called into question the primacy of personal and social taste and practically abolished it by showing that a work of art can be particularly capable of being collected and valuable when nobody likes it - including the artist who produced it, the curator who 
bought it and the society who paid for it.

Finally, there is always the recurring attempt to comprehend the collection as a representation of space in which different periods, cultures, nations and recently under the influence of the 'ideology of political correctness' - all other possible things that are different are aesthetically represented as well. Consequently, a collection begins to look like an expanded version of a democratic parliament. The major problem with this theory is that the particular thing that is socially, politically, ethnically or sexually 'different' does not necessarily produce another kind of art that may be distinguishable at the aesthetic level from all the other works of art in the collection. It is quite possible - and indeed it does frequently happen - that a work of art which is meant to represent aesthetically a specific social group becomes general, trivial and indistinguishable itself. And that means that this work of art cannot properly carry out its function of representation. The social, external difference does not guarantee an internal, artistic, aesthetic difference. An 'authentic' work of art can possibly prove to be totally banal, conventional and, in this sense, superfluous for the collection. The plurality of the art phenomena is not to be attributed to the plurality of the social groups that they are supposedly representing.

The difficulties with these and other comparable answers have led to a certain state of perplexity in which current art theory finds itself at the moment. My proposal would therefore be to try to find a way out of this perplexity by seeking the criteria of value for the collecting and preserving of works of art within the collection and in keeping with the collection's immanent logic ra- ther than looking for them outside the collection. A work of art is not collected when in external reality it has proven to be important and valuable in this or that respect, but rather only when it meets the internal criteria of the collection itself. Just as a picture today is not a picture of external reality, neither does the art collection as a whole merely represent external reality.

\section{II}

At first glance such a proposal contravenes the main intention of the modern trend in art. As a matter of fact the modern artist protests primarily against the power of the collections and the collectors - and, above all, against the power of the museums which are constantly compared with graveyards of art in the pamphlets of the artistic avant-garde, and the museum curators with gravediggers. The struggle of the modernists against the museum's historically traditional, defunct conventions of art were considered in the context of the avant-garde to be a struggle of life and death - as a protest of the present against the defunct traditions of the past that have found their place in museum collections. The logic of the collection was therefore understood to be the logic of death, deathly logic; resistance against it was to be the foremost duty of every vigorous art.

The internal presupposition for this struggle against the museum collection was the conviction that the museums acclaimed and collected only the art that conformed to the traditional criteria of artistic design and quality. A new, original, innovative art was by contrast considered to be an alternative and, above all, independent, art which enabled the artist 
76 to express himself and articulate the time in which he lived. The museum was looked upon as an institution whose cultural predominance prevents such an independent, original, vivid articulation.

In reality the situation is exactly the reverse. Where collecting is not done, it actually makes sense to remain faithful to the old, to follow tradition, and resist the destructive work of time. And so in the past Homer's poetry was learned by heart because it did not propagate anything else. Or new works were commissioned in the traditional style because old works of art were constantly destroyed. But if the old is collected and preserved in museums, replication of the old styles will become superfluous and it will no longer be worth the while to preserve them in the collection. A surplus of the same texts or pictures in the same collections will not be needed. Where Homer's poetry is written down and disseminated, there won't be any need to write like Homer. And if the traditional works are preserved in museums, there won't be any need to replicate their styles. The museums of the 19th century were from the start aesthetically very heterogeneous, and this was especially the case at the end of the century. They contained the most diverse examples of European art of the different periods as well as Chinese, Japanese or Egyptian art. There wasn't any uniform tradition which could have been conformed to. On the contrary, the internal structure of museum collections, where every historical period was represented by an aesthetic style only for itself, exacted the production of such new historical styles. The historicist logic of museum collections itself called for a different innovative, alternative art in order to expand these collections. The avantgarde was from the beginning the answer to this demand because a traditional, imitative art had no more any chance to secure a place for itself in museum collections. It had become redundant.

In this sense the avant-garde - despite its energetic rhetoric - realized that its own present was an already defunct present dominated by museums - a historically self-contained, aesthetic style which was supposed to take its place in a historic, museum comparison of all times and all styles. The attempt to aesthetically represent the present and even the future, just as the Futurists wanted to do, led to the development of the dynamic of an avantgarde, which because of its increasingly pluralistic diversity could no longer claim an exclusive right to representation. A single avant-gardist style could no longer function as an aesthetic signifier of its own time. For the first time in history the representation of history was no longer discovered post factum, but rather freely invented. Historical styles of the past have historically developed without reflection. They first had their importance as an aesthetic representation of the historical in the context of the museum of the 19th century. By contrast, the art of the avantgarde was produced from the beginning with regard to its potential position in the space of the historical comparison. The avant-garde began to develop its artistic activity in deliberate opposition to the art of the past in order to aesthetically structure the present and the future. The museum representation does not follow in this century any more a spontaneously and temporarily self-contained aesthetic development. This representation rather 
precedes such a development, first enabling this development and determining its course. The new art is not compared with the old post factum, rather the comparison takes place before the emergence of the new art - and virtually produces this new art. The art of the avant-garde is consequently a product of a comparison in the museum - that is also the reason why its forms are so diverse, for this comparison can be interpreted in many different ways.

Thus, from the beginning, avant-gardist innovation did not arise as an expression of spirited artistic freedom, but rather under the constraint or even oppression imposed by the collection. The artist had to produce the new to be included in the collection. This constraint was at first camouflaged by the rhetoric of artistic freedom, although some shrewd observers at the time had already sized up the situation correctly. The identification of freedom and innovation is indeed very naive. Freedom consists in being at liberty to produce the old as well as the new. But such freedom has never been permitted in modern art. The replication of the old was considered rather the output of inferior imitators, as Kitsch or, as we say today, department store art - and consequently banished from the museum. That is why there is no need to seek the reasons for the development of avant-garde's art in the external reality. It is enough to point to the compulsion towards the new which proceeded from the museum collection.

Above all the art of the avant-garde cannot be regarded as an expression of the personal will of an individual artist. Each artist of the avant-garde changed his style frequently in order to outdo other artists. He proceeded strategically and always had the general situation in view to better situate himself and his art in the general situation. Just as the new art cannot be regarded as an authentic expression of the individuality of a single person, neither can it be regarded as an expression of its time or its society. It was rather alien to its time and its society because it was based on collecting defunct art of the past whose outlook presumed a certain amount of special knowledge and experiences. The art of the avant-garde is the art of an elitist-thinking minority because it originates under a constraint to which the general public would not be subjected.

Time and again the artistic avant-garde has been connected with technological progress. It is a commonly held opinion that innovation in art has to do with technological innovation. But what is usually called technological innovation is in fact only a technological improvement. It is an advancing movement in a certain, prescribed direction. Someone whose name has slipped my memory at the moment wrote an article which splendidly sums up this difference with this example: A plane with only one wing would not be an innovation in technology because that wouldn't be an improvement, but in art such a plane would certainly be an interesting innovation. In art no bounds are imposed on innovation, save the bounds of the old and of tradition which should not be replicated at least not without some reflection.

On the other hand, having said that, means the new in art should not be associated with history and historiography in general. An artistic innovation is not a new step in the direction of a linear time. Although it represents the historical, the space of the museum itself is unhistorical, 
BORIS GROYS

78 just like a library of novels, for example, is still not a novel. We can therefore detach the term innovation from its association with the linearity of historical time - and hence we can also detach it from its association with the term progress. The criticism of progress or the historical utopias of the modernists is basically the criticism of the philosophical construction of a linear time. Such criticism becomes unvalid when artistic innovation is no longer thought of in terms of temporal linearity. And indeed innovation does not occur in time, but rather on the boundaries between the collection and the ouside world. And these boundaries between the museum and the outside world are not temporal, but are determined by a quite different, namely spatial, logic.

A Chinese statuette from the third millenium B.C. can be just as new for the collection - but not new either - as objects from the present and the future. The boundaries of the collection are constantly fluctuating and open to different times and places. Individual innovations that entail being included in the collection - or being removed from it - do not generally constitute history, although they have an impact on the entire state of the collection and change the logic of other innovations. As stated, these changes and restructurings do not lineate. They are selected points and define, or even continually invent their own historical past anew. The collection, however, remains compulsive because it predetermines through its own logic the innovations so that they allow this collection to expand.

Innovation should not be considered a creation. Man cannot create something out of nothing - that is still a divine privilege. For that reason all theories of art which attempt to interpret the creation of art as something produced from nothing or as a revelation of what is concealed are more than problematic. For innovation everything is always open, unconcealed, accessible. Innovation lies in the fact that something is included in the collection which had not been included before. The issue in this case is the shifting of the boundaries between 'valuable' works of art which are preserved inside the collection and the profane objects outside it. Certain profane objects can be chosen by a specific artistic strategy and placed as innovation in the context of the museum collection. Of course, this description of innovation refers primarily to the ready-made method that Duchamp introduced into art and to a large degree dominates the practice of art today. But the ready-made method should not be misunderstood as a particular art trend within a diversity of other methods. The ready-made method is only a demonstration of what art has always produced - a reflection of art practice as such and its internal regularities.

Art history shows that new trends in art have always arisen as a result of this strategy, that something which had been outside the valorized collection before, has been included in this collection. Consequently, the art of the Renaissance replaced Chris-tian icons with pictures of the immediate social surroundings. The Romantics exalted the unfinished and the subjective which had been previously excluded from acknowledged collections. And the art of the avantgarde exalted the primitive, the mechanical, the coincidental, the heterogeneous and many other things. It is not true that a work of art is produced at first quite spontaneously and, as it were, "outside 
culture" from an, as Kandinsky put it, "inner necessity" only to be evaluated afterwards as to whether this work of art can be included in the collection or not. The act of creating art is rather identical to the act of inclusion in the collection. Creating a work of art means putting something in the context of the collection which had not been represented in the collection before.

The general form of innovation is the re-evaluation of values, the shifting of hierarchies which place profane objects in the context of acknowledged values. As already mentioned, the museum comparison precedes the creation of art and defines it. When an artist upgrades a certain profane object which has not been included in the collection, he establishes an aesthetic signifier for his time and for himself. However, it still has to be determined if this feat of a single artist will be acknowledged by society and if the respective work will actually be included in the collection. But this social decision is in no way unrestrained or arbitrary either; it follows the same logic of museum comparison - but at a higher level of control.

Neither a single artist nor an institution has de facto the right to decide what goes into a collection and what not. The growth of the collections follows the law of the economics of innovation: only that which is original, new, unique and clearly breaks away from the prototypes is included in these collections. Many of the theories oriented along the lines of the art of the avant-garde have tried to prove that innovative art that does not follow certain rules of art production is also art. Most of the modern theories of art were thought up to legitimize the new art. But in the process the fact was overlooked that tradi- tional and not innovative art needs to be legitimized because of all things art produced according to familiar rules is not included in the collections, that means it is not regarded as serious, high art. By contrast, a legitimation of innovative art is superfluous; its success is the result of the logic of the collection itself.

Creating art is therefore identical with collecting art. Duchamp's ready-made method gave a clear idea of this internal identity between creating art and collecting by the way of the fact that ready-mades did not change - or only minimally changed - on the outside when they were valorized so that the wrong impression cannot arise that this change ( $\mathrm{i}$ e the shaping intervention of the artist) and not the logic of the collection constitutes the actual foundation for the assessment of the work of art as art. Nevertheless, such a shaping, artistic intervention still takes place - and Duchamp's ready-mades, by the way, do not constitute any real exception. For this reason the question that arises is what does this artistic intervention have as its aim. For art consumption which has to meet the public's conceptions regarding what art is and should be, the artist intervenes with the aim of adapting his material to the common traditional rules of art production. By contrast, in the art created for the collection such a shaping intervention serves the aim of purifying the respective, selected, profane object from all possible associations with traditional art. It could also be said that a shaping intervention serves the aim of shaping this object into one that is even more profane than it already has been in profane reality by underlining the contrast between this profane object and the traditional aesthetic norm. 
When it is frequently said that generally non-art instead of art is being produced today, that is true, of course. But that does not mean that it is very easy to produce non-art. It is not true that a small island of art is surrounded by a sea of non-art so that it is simply enough for the artist to dare a step over the boundary of acknowledged art in order to reach non-art. Profane reality is saturated with the art output. Our visual surroundings are constantly being artistically designed - indeed in the sense of conformity to the prevailing artistic norms. Furthermore, quite a lot from the space of the profane has already been aestheticized and included in collections. On the other hand, that means that it is difficult to find the potentially new profane reality in order to place it in the context of the collection. Therefore, in the case of this 'putting in context' through the intervention of the artist in the respective object selected for it, everything is emphasized that gives an idea of what brings this object in opposition to the already existing prototypes from the collection. In the case of such an intervention, therefore, everything that is contrastive, different, strange, alternative is brought to the fore which remains unnoticed at a superficial glance. The deliberate artistic stylisations or aesthetisations of, for instance the pictures of the insane, look even more insane than these pictures themselves. And technique in art looks even more technical, the spontaneous more spontaneous, the ugly uglier, the primitive more primitive and the exotic more exotic than in profane reality.

Here we have something to do with a phenomenon that can be defined as a negative conformity to traditional rules of art. One conforms to these rules by not breaking them. Incidently, the process does not differ very much from a positive conformity to rules of tradition to which these rules hold as strictly as possible. In both cases knowledge of the rules is taken for granted, and reference made to these rules plays the decisive role. In both cases the outcome is not reality, but fiction. Only in one case it is a fiction of positive conformity where life supposedly looks just like the traditional artistic ideal, and in another case life is presented in reverse as non-art, as a radical alternative, as something opposed to the ideal. But both outcomes are equally fictional - the avant-gardist non-art is just as artificial and produced according to certain rules as traditional art. And that is the reason why both can be represented in collections on the same scale.

The problem with negative conformity, i. e. the production of non-art, is now and again - and especially recently - not only underestimated, but also overestimated so that it is constantly claimed that there is nothing new to be found any more as all boundaries have been crossed and all taboos have been broken. The collection allegedly no longer differs from profane reality. But this assessment does not apply right away. It must not be forgotten that the pictures of high art become profane, inasmuch as they find their way into profane reality - even if they remain outwardly the same. Walter Benjamin, among others, has convincingly proved this in his observations on the loss of the aura. The change of context in which art objects function as well as methods of their dissemination lead to changes in their reception which can then be aestheticized and 
absorbed into the collection in the second round of the aesthetisation of the profane.

This is the way so-called post-modern art actually functions. The post-modern artist inquires about changes objects of art undergo in profane reality of the modern mass society and the media and he aesthetisizes these changes. This process is often misunderstood when it is believed that post-modern art produces nothing new because it only borrows from the art of the past. But this reproach is not justified because borrowings are not being taken from the art of the past itself, but rather of the profane mass appearances of this art, i. e. classical art, which has gone through the meat mincer of the mass media and mass reception. Here the attention is transferred from the novelty of the artistic form to the novelty of the social, media and linguistic handling of this form - and this transference is fully legitimate.

But there is still a deeper reason for the fact that the preoccupation with non-art does not lead to the disappearance of the boundaries between art and life, or between collection and profane reality. The collection is also on the whole more profane than life just as any single work of modern art is much more profane than anything in everyday life. The traditional conception of art assumes that order and hierarchies are established in art which lend art value. Art has value because it is higher, and it is higher because it establishes an hierarchic order which is missing in life. Profane reality is described in the process as the realm of entropy, or at least 'entropization' that constantly threatens and undermines all order. The battle for art, for culture, for civilization is therefore regarded as the battle of forces bringing about order against the entropy of death which threatens everything living.

If this is actually so, then it has to be stated that the art of today has lost this battle for the old and the new order as well because it obviously offers a picture of the very far advanced entropy. It appears to be arbitrary, chaotic, excessively pluralistic and as a consequence no longer brings about order or meaning. Art is apparently no longer elevated over life. It has dismantled its own hierarchies so that society does not understand any more what value art should have. This situation is quite new - it should not be understood as familiar. The preoccupation with nonart, the disbanding of the old order is actually an old avant-gardist story, and one may possibly wonder why the question about the value of art is being brought up nowadays with such an intensity which is threatening all the existing collections with total debasement. It is plausible to say that we are in no way dealing with a new historical phenomenon here. Just trends are becoming visible today and clear for the masses who characterized the artistic dynamics from the beginning of modern art.

Such a claim is, of course, thoroughly correct in itself. But in this case the fact is overlooked that modern art has known up until now how to legitimize its ventures against the old order, always with the hope of a new order. Today we are experiencing for the first time the fundamental crisis of such legitimation. Since the Renaissance and on through the Romantic period and until the end of the 19th century, the new European art has been legitimized by means of a humanistic ideology. In denying traditional prototypes, conventions of the past and the traditional defi- 
82 nition of mastery, self-assertion of human freedom was considered liberated from all the chains of prescribed taste and directly related to nature. The new art hence conformed with a new hierarchy which had individual freedom at its pinnacle. Art thus retained its traditional function and value. It still expressed a hierarchy of values which was supposed to dominate reality itself.

\section{IV}

The new art underwent another evolution when in the times of the historical avantgarde it was linked to diverse theories of the unconscious which have put the autonomy of human freedom in doubt. For Nietzsche, Freud, Heidegger, Wittgenstein and Saussure and their successors, only the 'other', the concealed unconscious, plays a determining role in life which people inevitably overlook. That is why the overlooked, the profane, the 'extra-cultural', the non-collected have been understood and assessed as a symptom and trace of the unconscious which secretly controls human action. Economics, sexuality, race, existence, language, textuality, writing, simulation and difference are the various names for the unconscious, whose signs can only originate from a hidden, profane reality because everything that is always included in collections is conscious by definition. The theories of the unconscious create their own hierarchies. At the top of these hierarchies is the overlooked profane, or non-art, which acts as a signifier of unconscious forces. The theories of the unconscious thus explain with credibility the main process and the dynamics of modern art which is continually searching anew for the overlooked in order to track down the unconscious. Even if, as some authors claim, the quest for the unconscious with the object of making it conscious, or at least characterizing it, is wrong in its basic intention, because the unconscious cannot be made conscious without ceasing to be the 'other', the sublime which has not yet been thought of, even then the denial of the dawning of consciousness of the unconscious can be made the central theme of art, because even then it is an issue concerning the unconscious as the most valuable and supreme. Even for the Deconstructivism of Derrida, who wants to break most radically with traditional assumptions of metaphysics, the textual unconscious still remains the supreme because it deconstructs every text and consequently actually controls. Today the different theories of unconscious structure and substantiate the hierarchic order of art just as much as the theories of human freedom did in the past. Individual artists are extolled because they give expression to the unconscious the way they were praised in the past for having made transcendental truths or the ideals of beauty visible.

The reason for the feeling of crisis of all legitimizations, which is so widespread today, arises from an explicit - but not completely open - doubt about the theories of the unconscious and legitimizing force. It seems that today we no longer have any unconscious because everything has become accessible to us and everything is allowed. The unconscious has been definitely taken over by the 'system'. But even the system can no longer act as an unconscious, that is as a social and political determinant that cannot be eluded - for one no longer knows what this system really consists of. But, regardless of whe- 
The Logic of the Collection

ther it is the supreme or the lowest, if there is nothing more that art can draw from or aesthetically represent or make visible, inevitably the question arises, why it should take up a specific, honoured space in social reality. The entire legitimization of the system art is traditionally based on the assumption that this system on the whole represents something that is the 'other' in reference to reality. If this 'other' - as God, idea, freedom, but also as the unconscious or hidden cultural identity - is no longer considered to be existent, art apparently loses its legitimization so that it is slowly threatened with disintegration into profane reality.

But as I have tried to show, the hypothesis of human freedom as an explanation for the dynamics of modern art is just as superfluous as the theories of the unconscious. This dynamics can be sufficiently and convincingly deduced from the inner logic of the collection itself, without having to invoke metaphysical, hidden forces, whether it be freedom and reason, whether it be unconscious life or language itself, or whether it be the unreflected mechanisms of the market or the power of institutions. Hence new works of art do not represent any new 'real' or 'vigorous' order. The growth of the collection exclusively follows the logic of collecting.

And that means further that the collection or the system art on the whole does not need any legitimization as an aesthetic representation of a hidden reality, an 'other', a super-conscious or an unconscious. If the collection is understood to be such a representation, then the 'other' is still sought beyond the collection - that is in reality. But the collection does not represent another reality; it is that other reality. In the collection, things function differently than they do in reality, in life. Instead of being consumed, they are preserved. The widely propagated demand to blast the boundaries of art in order to get directly at life overlooks the fact that art always has been a form of life - but another form of life. To overcome it does not mean coming to life, but rather simply destroying a particular form of life.

If the question is asked, what is meaning in art, the answer should be in fact 'no meaning', if the term 'meaning' means that art could or should denote some 'extra-cultural', 'extra-artistic' reality. On the other hand art is closely related to this 'extra-artistic' reality - especially to political reality. But the relation of art to politics should not be taken as the object of a personal artistic-political committment. An individual artist cannot decide whether his work should be political or not; the political relevance of his own art is not available to him. Neither does a critic have the criterium of differentiating between diverse works of art with respect to their political significance and function. The collection itself is rather a figure of the political. For the political belongs to the life of the collective. The type of collection makes it clear, therefore, how the lasting forms of culture and social life in general are stabilized and handed down and how the general framework of the constantly changing political events and phenomena is shaped. The collection constitutes such a framework for the collective. The form of the collection shapes the time and space in which the political occurs and at the same time makes it visible. Art therefore denotes the general context of the political. To reduce it to a concrete political exertion of influence 
84 within this context would mean underestimating its much deeper political relevance.

In order to elucidate what has been said, I would like to refer to at least three historic forms of art representation that I mentioned at the beginning: the church, the palace and the modern collection. Despite all the considerable differences which I cannot go into right now, in the church and in the palace works of art are presented in a rigidly hierarchic manner. The meaning of a single work of art is determined by its place in the correspondingly structured hierarchic collection. And it can be said that every single work of art in these collections internalize their general structure. It is just as structured and ranked hierarchically inside itself as the space of the church or palace. But what remains the presupposition for such a hierarchic organization is the fact that all elements of this organization can be substituted: In a church an old fresco or an old icon can be quite easily removed or destroyed and replaced with new icons and frescoes. The fact that these new works of art are completely different in style does not influence their hierarchic position and hence their value for the collection.

By contrast, the modern collection, as stated, is structured on the principle of preserving the old. Accordingly, the new does not find its place in the collection in lieu of the old, but rather alongside the old. But from this results a new impossibility of hierarchic order. The space of the collection, where the new is placed on the same scale and on the same level of value with the old, thus loses its previous hierarchic character. It eliminates hierarchies and it neutralizes, deconstructs, homogenizes the space which becomes unqualifia- ble and indescribable. Incidently, modern art reflects this new space of the collection just as much as it did the art of the church and palace in the past. The modern work of art in itself also increasingly eliminates hierarchies, is increasingly decentralized, deconstructed and neutralized. Modern art continually tries to absorb this undefinable, completely neutral space of the collection which eludes every description and modern art continually tries to demonstrate this in the single work of art. But this never succeeds completely, because every new work of art receives a place in this space of the collection which it can no longer reflect in itself, that is the space among the works of art and not within these works of art - even if these art works are organised in themselves as small museal collections, or installations.

A modern political representation is also accordingly structured. It is increasingly shaped as a collection of varying political, social, ethnic and sundry standpoints, none of which offers the possibility of overlooking the entire collection, and at the same time the invention of a new political standpoint too cannot be interpreted as merely a representation of an already latent, unconsciously existing political reality. It is rather a matter here of a genuine opening up of a new political way of life. In its neutrality and deconstructiveness the artistic space of the collection is certainly much more radical than the space of political representation which remains certainly structured as hierarchically as ever before. This radicalness of the artistic space can be interpreted as a challenge to politics to come even closer to this space. But it can also be claimed that in its supposed neutrality the artistic space rather camouflages, improves appearances and 
hence ideologically legitimizes real political relationships. Both interpretations are deeply anchored in the entire history of art. It can be found too in the discussions about the relationship between Christian art and secular political order. The artistic space is most profoundly related to the political space in its basic structure. But exactly this inner relation provided the possibilities for further affirmation or criticism of the prevailing political order on the part of art.

The museum collection is in fact more pluralistic, more homogeneous, more entropic than the actual society that we are living in. And that explains why and how the modern collection functions as a legitimization of the modern pluralistic State which dominates the much more homogeneous society. The traditional idea of power presupposes that one specific social stratum, or ideology dominates direct or indirect - an intrinsically pluralistic society consisting of many different strata or ideologies. But the modern State represents much more standpoints, traditions - past and present - cultural forms and ways of thinking than the factual society dominated by this State. And the modern museum makes precisely this difference between State and society in their structural inner plurality immediately obvious. The society can stand such a comparison because it is not so rich in political standpoints and cultural attitudes as the Museum. The Church dominated the society, or the world because the world was seen as sinful. The Palace dominated the society because the non-aristocratic population had no good taste, no manners and no style. The modern Museum dominates the society because the society compared to it - seems to be too trivial, flat, homogeneous and boring.

The shortest definition of a space of modern collection would be: it is the space of entropy. This entropy of the collection is, however, just as artificial as the traditional order. It is produced and not simp-ly given. The term entropy is as a rule negatively loaded because it is believed that life, as has already been stated, needs order, and that entropy threatens therefore to destroy every life. But precisely this threat makes up the fascination of entropy and the 'entropisized' space. The collection as a place of preservation is indeed at the same time a place of death as well as the site where the attempt is made to overcome death. The church was also such a place of death, where one felt threatened by the superior order - and at the same time one hoped for salvation. In the past death was considered to be a sut sumption under a superior himrshic order. Today death is considered to be a pure disintegration into a horizontal infinity - into a neutral space of the entropic. The space of the collection is therefore an attempt to survive in entropy and by means of entropy - to overcome entropic death through the entropy itself. This dream of survival in entropy conditions the fascination of modern art on the whole as well. Every at-tempt to force a new, life-securing order on this art, fails because such an attempt overlooks the real problem and thus proves to be naive.

Entropy goes deeper than all antitheses like chaos vs. order, ecstasy vs. normality, primariness vs. secondariness, language vs. writing, crime vs. morality etc. with which the theories operate in an attempt to fix a certain essence to art. But by way of the actual artistic occurrence all these theories are simply placed alongside each other in 
86 a collection and levelled in the process. Where order tries to assert itself in the art of today, there arises at once the trends which forebode chaos. Where chaos is more intensely emphasized, art reacts with new principles of order. Where the abundance of pictures prevails, one expects and gets the pictures of emptiness. Where art becomes temperate and ascetic, there is hunger for pictures. Where morality is preached, one begins to praise crime and vice versa. Every move in a direction is immediately compensated, blocked and made ineffective by the movement in another, counter direction. But even the models with which one tries to describe this situation such as the dualistic Ying and Yang laws, for example, do not function. Where dualistic models turn up, they are confronted by monistic models. All these movements in thought and style seem to be contradictory and chaotic. But altogether they vouch for the state of entropy in which the space of the collection finds itself. On the whole they vouch for the neutrality, the indescribability and the non-representability of this space which cannot be occupied by any single work of art or any single theory either.

But, as already stated, this space is not a space of outer reality, but rather it is the space of the art collection itself. When art is produced, this space is created and designed along with it - even when and especially when one does not manage to represent this space within one's own work. Ever since the 'Black Square' of Malevich, at the very least, efforts have been made time and again to create the picture of a total, neutral, empty space - through reaching a zero level of the picture, through a random accumulation of heterogeneous materials and objects, through endless, undifferentiated monotony, through the unmotivated repetition of what already exists, or through the consequent rejection of every statement, to name briefly just a few of the corresponding strategies. Nevertheless, the 'entropic' space of the collection remains the largest and, if you will, the only work of the Modern art because it cannot be represented individually. The structuring of this space is executed through the collective work of expansion and transformation of the collection in which artists as well as curators, private collectors, gallerists and critics take part on an equal basis. The art historians' attention has been concentrated much too long on the individual achievements of modern artists. They seemed to be too heterogeneous and therefore aroused not only admiration for their boldness and freshness, but also nostalgia as well. There was a longing for a collective artistic work where the contribution of the individual served the expansion and improvement of the whole. Perhaps only now it can be realized that this collective work was achieved in the work of the modernists too, and that the heterogeneity of the individual contributions served in the end the extension of the neutral space of the museum collection which in its entirety struc-tures and marks our time just as the spaces of the churches and palaces have put a mark on the past.

Boris Groys blev efter studier i matematik och filosofi vid universitetet $i$ Leningrad, vetenskaplig medarbetare vid Instittutet for strukturell lingvistik vid Moskvas universitet 1965-71. Från 1981 har han bott $i$ Tyskland och är verksam som skriftställare och publicist samt knuten till filosofiska institutet, Münsters universitet. Hans bok 'Gesamtkunstwerk Stalin', som utkom 1988 har väckt stor uppmärksamhet.

Adr:Schwalbacherstrasse 17, D-5000 Köln 51, BRD. 